Cite this: RSC Advances, 2013, 3, 18300

\title{
Effect of ionic liquids on the conformation of a porphyrin-based viscometer $\dagger$
}

Received 16th June 2013,

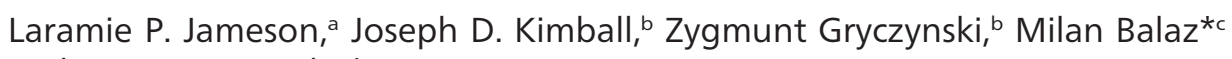

Accepted 1st August 2013

and Sergei V. Dzyuba*a

DOI: $10.1039 / c 3 r a 43001 d$

www.rsc.org/advances

Structure of the cationic and anionic counterparts of ionic liquids has a significant impact on the conformational bias of the porphyrin rotor; an apparent correlation between the conformation and the viscosity of ionic liquids was noted, albeit it was found to be distinct and more complex from that found in molecular solvents.

\section{Introduction}

Ionic liquids (ILs) are materials comprised exclusively of ions, and have phase-transition temperatures at or below room temperature. ${ }^{1}$ ILs have found numerous and ever-expanding applications in various areas of science and engineering. ${ }^{1-7}$

Virtually unlimited structural variations of ILs, which can be obtained via well-developed synthetic routes, are likely to give rise to distinct physicochemical properties such as phase transitions, density, viscosity, polarity, hydrogen bonding abilities, etc. ${ }^{8}$ Arguably, these physical properties could have an impact on solutes, and therefore, the ILs can be designed to control the outcome of a given process by simply varying the structure of cationic and anionic components. This has led to the idea of ILs as designer solvents. The designer solvent ability has been defined as the manipulation of a structure and thus physical property of the IL which can predictably alter the outcome of a given process. ${ }^{9,10}$ As such, this paradigm has been illustrated through several synthetic transformations. ${ }^{9-11}$ However, applications demonstrating the designer solvent ability of ILs outside of their use as milieu for synthetic organic transformations appear to be limited. Notably, it was demonstrated that structural changes

${ }^{a}$ Department of Chemistry, Texas Christian University, Fort Worth, TX 76129, USA. E-mail: s.dzyuba@tcu.edu; Fax: +1 817257 5851; Tel: +1 8172576218

${ }^{b}$ Department of Physics and Astronomy, Texas Christian University, Fort Worth, TX 76129, USA

${ }^{c}$ Department of Chemistry, University of Wyoming, Laramie, WY 82071, USA. E-mail: mbalaz@uwyo.edu; Fax: +1307 766-2807; Tel: +1 307 766-4330 $\dagger$ Electronic supplementary information (ESI) available: Details on the synthesis and purification of ILs, characterization data of PD, sample preparations and physical properties of ILs and molecular solvents and their mixtures as well as additional spectra. See DOI: 10.1039/c3ra43001d within either the cation or anion could be used to modulate the conformational flexibility of a small molecule. ${ }^{12,13}$ Possibilities for using neat ILs to control intermolecular interactions have been suggested primarily for cyanine dye self-assemblies. ${ }^{14}$

Studies on viscosity of ILs using fluorescent dyes has been a subject of interest, ${ }^{15-17}$ and the use of fluorescent probes for understanding the structure of ILs, in general, has been recently reviewed. ${ }^{18}$ In addition, it was shown that the viscosity of molecular organic media could control the conformation of a conjugated porphyrin dimer (PD), resulting in an array of conformations with two distinct extremes: a planar and a twisted conformation (Fig. 1). ${ }^{19,20}$ This characteristic is unique for this particular probe, as many fluorescent molecular rotors used for viscosity studies report on viscosity primarily through an emission enhancement $^{21}$ or lifetime measurement, ${ }^{22}$ rather than a distinct wavelength. A linear dependence was observed between the conformational preferences of $\mathbf{P D}$ and viscosity of the media. ${ }^{20}$

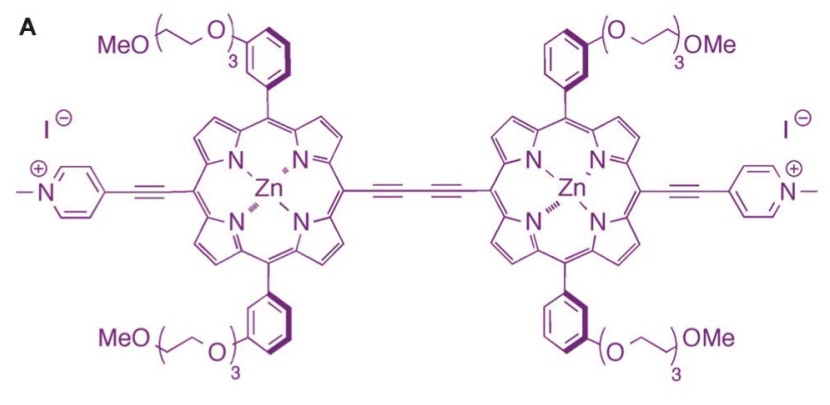

B

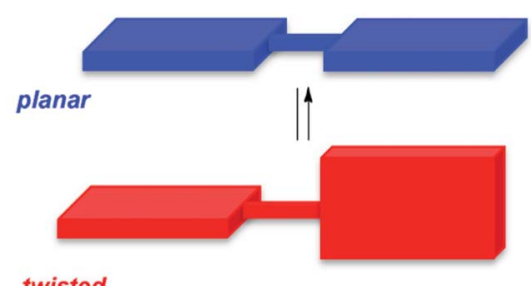

twisted

Fig. 1 Structure (A) and conformational extremes (B) of PD. 
Importantly, planar and twisted conformations exhibited distinct emission maxima: $710 \mathrm{~nm}$ for twisted and $780 \mathrm{~nm}$ for planar, which allowed for a facile and straightforward evaluation of the conformational preference of PD. Specifically, in non-viscous media, e.g., methanol, the planar conformer was shown to predominate, while in more viscous methanol-glycerol mixtures, the twisted conformation was observed..$^{20}$ Thus, PD was proposed to be a suitable probe for an investigation of the media's viscosity.

Conversely, viscosity of the media might be viewed as a physical property that could control the conformation of PD. Because the viscosity of ILs can easily be tuned by varying the structure of the cationic and anionic counterparts, ${ }^{8}$ we investigated whether the conformational preference of PD would be altered as a consequence of changes in the viscosity due to

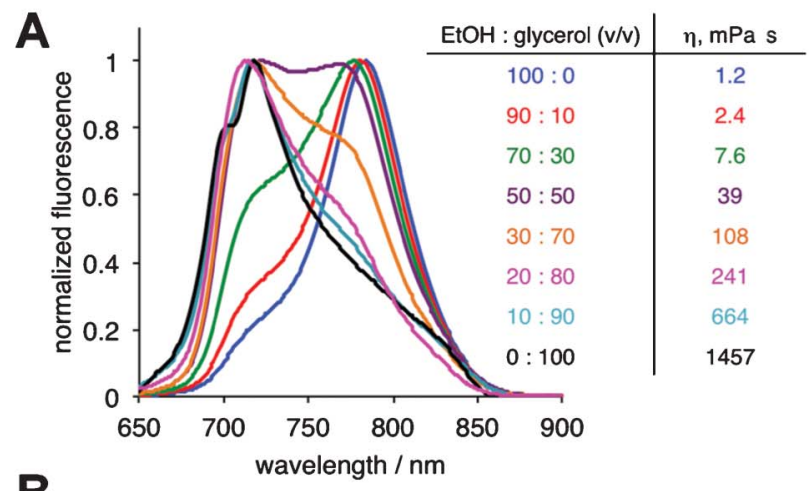

B
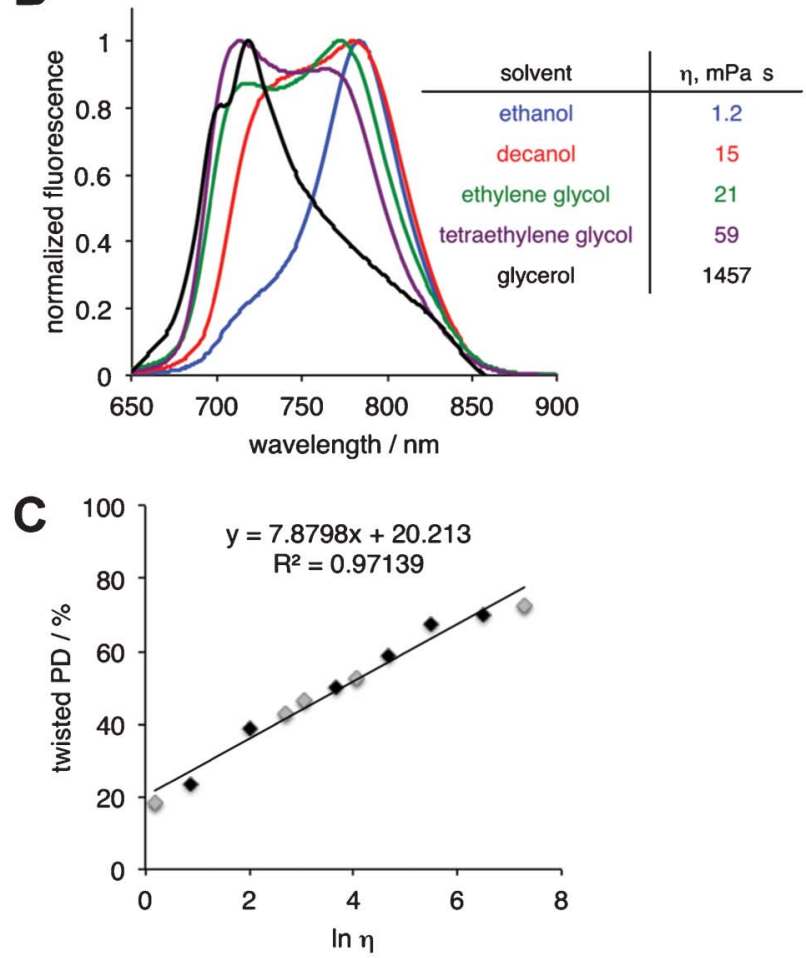

Fig. 2 Emission spectra of PD in EtOH-glycerol mixtures of different viscosity (A), single component molecular solvents of different viscosity (B), and effect of media's viscosity on \% of twisted PD (C, black diamonds - EtOH-glycerol mixtures, grey diamonds - single component solvents). Conditions: $\lambda_{\mathrm{ex}}=470 \mathrm{~nm},[\mathrm{PD}]=1 \mu \mathrm{M}$, all mixtures contain $0.1 \%$ DMSO (v/v). variances in the IL structure. As such, this could also be used as a corroboration of the designer solvent ability of ILs, ${ }^{9,10}$ as well as a demonstration of the distinct nature of ILs as compared to the molecular solvents.

First, the fluorescence spectra of PD were measured in ethanol, glycerol and their respective mixtures (Fig. 2A, see Table S1 and Fig. S1 for additional informationt).

Next, in order to evaluate the scope of single component molecular solvents, the physical properties of more viscous decanol, ethylene glycol and tetraethylene glycol were also measured (Fig. 2B, see Table S2 for additional information†). Qualitatively our results were in complete agreement with the published data: ${ }^{20}$ the planar conformer of PD dominated in less viscous media, whereas the twisted conformation started to dominate in more viscous media. Specifically, the switch from the planar to the twisted conformation of PD took place at a molecular solvent viscosity of ca. $39 \mathrm{mPa}$ s. Notably, a good linear correlation between the viscosity and a conformational preference of PD was found (Fig. 2C).

In order to examine the correlation between the conformational preference of PD and the viscosity of ILs, we employed ILs based on one of the most commonly used cationic components, i.e., 1-alkyl-3-methylimidazolium, $\left[\mathrm{C}_{n}\right.$-mim]. It is well known that the viscosity of this type of ILs can be altered by varying the length of the alkyl chain as well as the identity of the anion. ${ }^{23-28}$ Hence, we prepared several sets of $\left[\mathrm{C}_{n}\right.$-mim]-based ILs (Scheme 1) in order to investigate the effect of viscosity on PD conformation and potential cation and/or anion effects.

ILs were chosen to cover a wide range of viscosities. ${ }^{23-28}$ In general, for 1-alkyl-3-methylimidazolium-containing ILs, increase of the alkyl chain length leads to more viscous ILs. It is also known that $\mathrm{NTf}_{2}$-based ILs are among the least viscous imidazolium-type ILs, while viscosity of $\mathrm{PF}_{6}$-containing ILs spans over a fairly wide range. In addition, $\mathrm{NO}_{3}$-containing ILs, which are generally much more hydrophilic than the corresponding $\mathrm{NTf}_{2}$ - and $\mathrm{PF}_{6}$-containing congeners, were chosen due to similarities in viscosity with the $\mathrm{PF}_{6}$-containing set of ILs. ${ }^{28,29}$ Collectively, this set of ILs would aid

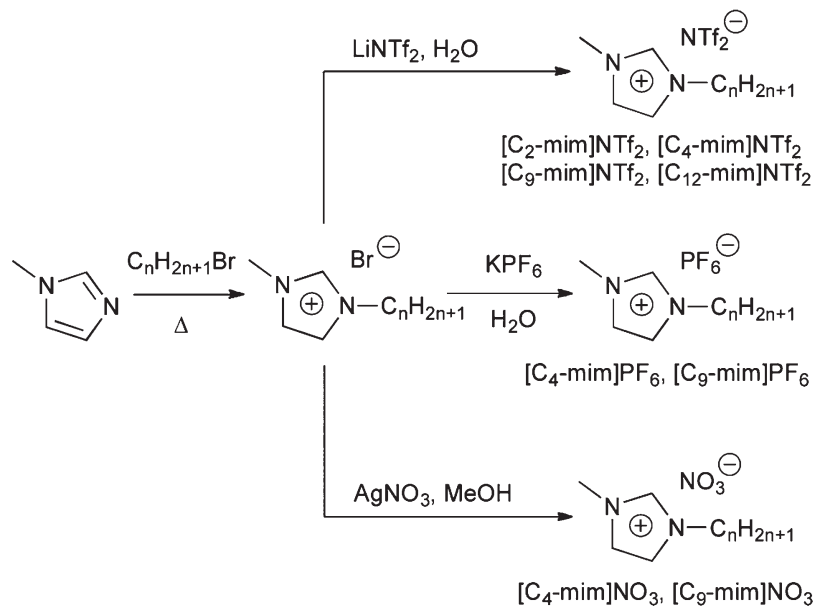

Scheme 1 Synthesis and abbreviations of ILS. 
in identifying possible anion and cation effects on the PD conformation.

Furthermore, the viscosity of ILs is known to be greatly affected by the presence of water. ${ }^{27,28}$ Therefore, the water content of all ILS was measured after the viscosity and spectroscopic measurements were performed (Table S3, ESI'). It could be argued that in order for the ILs to be viable from the practical standpoint, all manipulations involving the ILs must be conducted on a bench top. As such, no attempts to reduce the amount of residual water in ILs, beyond commonly applied azeotropic water removal and vacuum drying were taken (see ESI† for further details).

Concurrent with water content measurements, we examined the conformational preference of PD in ILs using fluorescence spectroscopy (Fig. 3). It should be noted that ILs are intrinsically fluorescent, and the origin of the fluorescence has been debated in the literature. ${ }^{29}$ However, a number of experimental and theoretical accounts from various groups have suggested that it is likely to be related to the microstructuring within ILs. ${ }^{30} \mathrm{Here}$, for all fluorescence experiments that feature PD, the fluorescence spectra of ILs were subtracted.

Viscosities of common imidazolium-based ILs are known to be orders of magnitude higher than those of many common molecular solvents, and as such the twisted conformation of PD was expected to be seen for all ILs with a viscosity of $c a .40 \mathrm{mPa}$. However, in contrast to molecular solvents (Fig. 2), IL $\left[\mathrm{C}_{2}{ }^{-}\right.$ $\operatorname{mim}] \mathrm{NTf}_{2}$, with $\eta=38 \mathrm{mPa}$ s significantly promoted the planar conformer of PD (Fig. 3A, see Fig. S1, ESI† for absorption spectra of PD in ILs). As the viscosity of the $\mathrm{NTf}_{2}$-containing ILs increased as a function of the alkyl chain length, the preference for the twisted conformation of PD increased as well. A similar effect was observed for the $\mathrm{PF}_{6}-$ and $\mathrm{NO}_{3}$-containing ILs (Fig. 3B and 3C, respectively). Thus, the cation of the ILs might have a significant role in the conformational bias of PD.

Furthermore, when the viscosity was plotted as a function of the twisted conformation of PD, an apparent correlation was observed (Fig. 3D), albeit the linearity was found to be somewhat poorer from that observed in the case of the molecular solvents (Fig. 2C). In addition, since the slope in the case of ILs is smaller than that compared to molecular solvents, i.e., 6.0577 versus 7.8798 , respectively, a significantly higher viscosity would be required for ILs to induce the twisted conformation when compared to the molecular solvents. Overall, within each set of ILs with a common anion, the percentage of the planar conformation of PD appeared to decrease as the viscosity of the IL increased (Fig. 3: A, B and C). For example, in all [ $\left.\mathrm{C}_{4}-\mathrm{mim}\right]-$ containing ILs (Fig. 3; see Fig. S2, ESI, $\nmid$ for overlaid spectra), despite $c a$. 6 -fold viscosity range ( 60 for $\left[\mathrm{C}_{4}\right.$-mim] $\mathrm{NTf}_{2}$ to 262 for $\left[\mathrm{C}_{4}-\mathrm{mim}\right] \mathrm{NO}_{3}$ to $381 \mathrm{mPa} \mathrm{s}$ for $\left.\left[\mathrm{C}_{4}-\mathrm{mim}\right] \mathrm{PF}_{6}\right)$, the planar conformation of PD was observed (although a linear correlation with viscosity was noted). This was reminiscent of the correlation with viscosity observed in the molecular solvents (Fig. 2).

However, upon closer examination of the aforementioned trend (Fig. 3D), it is evident that the viscosity of the ILs might not be a dominant factor in controlling the conformational bias of PD. Specifically, when comparing the viscosities of $\left[\mathrm{C}_{12}\right.$-mim $] \mathrm{NTf}_{2},\left[\mathrm{C}_{4^{-}}\right.$ $\mathrm{mim}] \mathrm{NO}_{3}$ and $\left[\mathrm{C}_{4}-\mathrm{mim}\right] \mathrm{PF}_{6}$, which progressively increased in
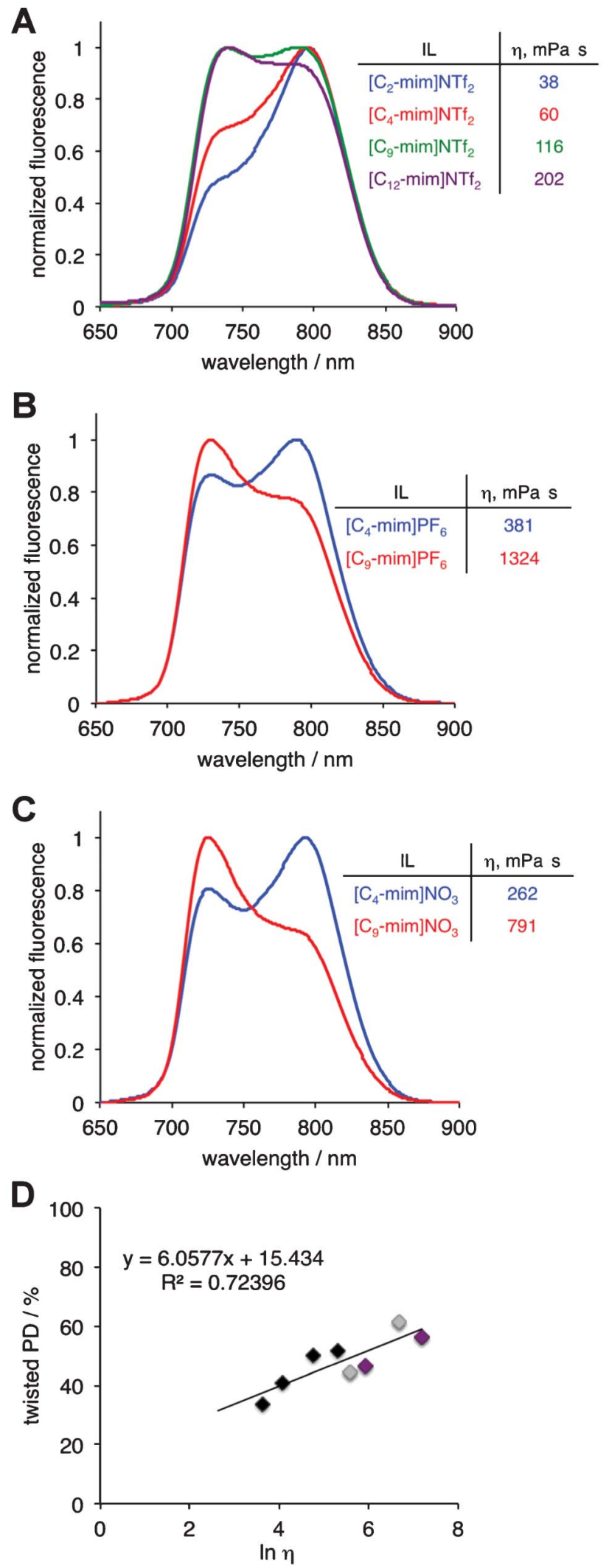

Fig. 3 Fluorescence spectra of PD in $\left[C_{n}-\operatorname{mim}\right] N f_{2} I L s(A),\left[C_{n}-\operatorname{mim}\right] P F_{6} I L S(B),\left[C_{n^{-}}\right.$ mim] $\mathrm{NO}_{3}$ ILs (C), and effect of ILs' viscosity on \% of twisted PD (D: [C $C_{n}-$ mim] $\mathrm{NTf}_{2}-$ black symbols; $\left[C_{n}-\right.$ mim] $\mathrm{PF}_{6}$ - purple symbols; $\left[\mathrm{C}_{n}-\right.$ mim] $\mathrm{NO}_{3}$ - grey symbols). Conditions: $\lambda_{\mathrm{ex}}=475 \mathrm{~nm},[\mathrm{PD}]=1 \mu \mathrm{M}$, all mixtures contain $0.1 \%$ DMSO (v/v). 
viscosity from 202 to 262 to $381 \mathrm{mPa} \mathrm{s}$, no correlation in regard to the PD conformation was observed (Fig. S3, ESIt). An inverse correlation was evident for $\left[\mathrm{C}_{9}-\mathrm{mim}\right] \mathrm{NO}_{3}$ and $\left[\mathrm{C}_{9}-\mathrm{mim}\right] \mathrm{PF}_{6}$ ILs (Fig. 3D, see Fig. S4, ESI $\dagger$ for overlaid spectra): with increasing viscosity of IL, the planar conformation started to dominate.

It is plausible that in ILs specific solvent-solute interactions (as well as the structure of ILs) could control the conformation of a small molecule, rather than the viscosity of the media. Unlike molecular solvents, which interact with solutes via dipole-dipole interactions and hydrogen bonding, ILs have the added ability to interact via ion-, and ion-ion interactions, i.e., via electrostatic interactions. It was also suggested that a significant amount of solute stabilization by ILs comes from the cation, ${ }^{30}$ which might explain the apparent cation effect observed here.

To gain further support for the notion that viscosity of ILs might not be the dominant factor in controlling PD's conformation in ILs, we examined the relationship between viscosity and conformational bias of PD as a function of temperature. Arguably, if the viscosity were the main factor that modulated the conformation of PD, then changing the temperature (and as a result changing the viscosity of the solvent) should result in a linear correlation between the viscosity and the percent of the twisted conformation of PD. Also, the slope should be similar to that observed for solvents of various viscosities at a fixed temperature. Conversely, if the slope of the viscosity (obtained at different temperatures) as a function of PD conformation would be different from the slope obtained for solvents of various viscosities at a fixed temperature, some specific interactions between the solvents and PD might be present.

To test this hypothesis, we examined the conformation of PD in several molecular solvents (Tables S4-5; Fig. S5, ESI†) and ILs (Tables S6-8; Fig. S6, ESI $\dagger$ ) at various temperatures and consequently viscosities (Fig. 4).

The slope of viscosity as a function of the twisted PD in EtOHglycerol $(2: 8 \mathrm{v} / \mathrm{v})$ mixture as well as tetraethylene glycol (Fig. 4A) appeared to be very similar to that obtained for various molecular solvents (Fig. 2C). Arguably, this indicated that viscosity of molecular solvents was the major factor that controlled the conformational bias of PD (See Fig. S7, ESI $\dagger$ for overlaid data points).

On the contrary, in ILs no apparent correlation among several different ILs was observed (Fig. 4B). Although for $\mathrm{PF}_{6}$-containing ILs $\left(\left[\mathrm{C}_{4}-\mathrm{mim}\right] \mathrm{PF}_{6}\right.$ and $\left.\left[\mathrm{C}_{9}-\mathrm{mim}\right] \mathrm{PF}_{6}\right)$ somewhat similar slopes were obtained, the two data sets were off-set. When the ILs with the same cation were compared $\left(\left[\mathrm{C}_{4}-\mathrm{mim}\right] \mathrm{NO}_{3}\right.$ and $\left.\left[\mathrm{C}_{4}-\mathrm{mim}\right] \mathrm{PF}_{6}\right)$, the corresponding slopes were found be distinctly different. Therefore, it is plausible that in ILs, solute-solvent specific interactions are playing a significantly more prominent role than viscosity. This is in contrast to the observation noted for the molecular solvents.

Finally, we decided to investigate the effect of water in $\left[\mathrm{C}_{4}{ }^{-}\right.$ mim] $\mathrm{NO}_{3}$ ILs on the viscosity of the IL (Table S9, ESI†) as well as the conformational preference of PD. Following the aforementioned rationale on the effect of temperature on viscosity and the conformation of $\mathbf{P D}$, we reasoned that the presence of water should alter the PD- $\left[\mathrm{C}_{4}-\mathrm{mim}\right] \mathrm{NO}_{3}$ interactions, which should produce a distinct correlation between IL viscosity and PD
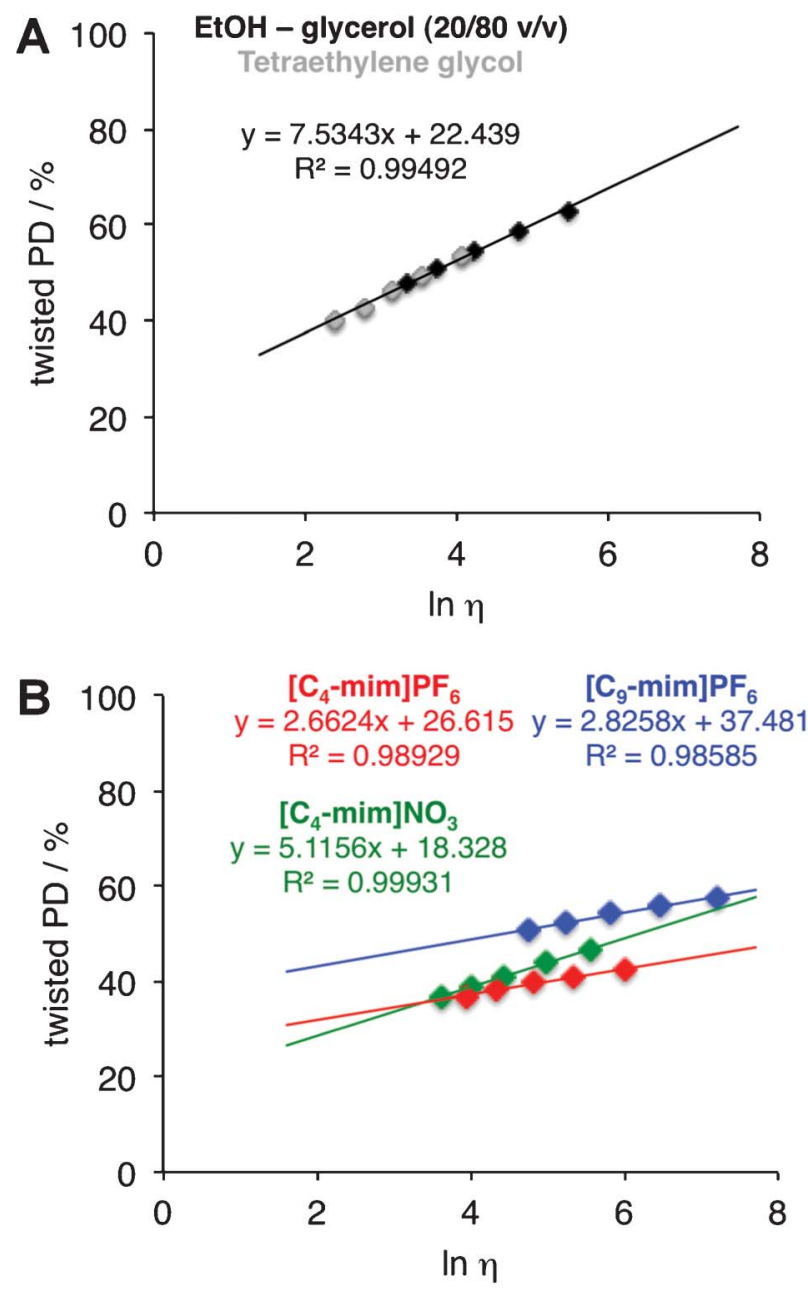

Fig. 4 Effect of solvent (A: molecular solvents; B: ILs) viscosity on \% of twisted PD measured at $20-60{ }^{\circ} \mathrm{C}$ range (see ESI for additional informationt); conditions: $\lambda_{\text {ex }}$ $=470 \mathrm{~nm}$ for $\mathrm{A}, \lambda_{\mathrm{ex}}=475 \mathrm{~nm}$ for $\mathrm{B},[\mathrm{PD}]=1 \mu \mathrm{M}$, all mixtures contain $0.1 \%$ DMSO $(\mathrm{v} / \mathrm{v})$.

conformation from that observed upon variation of temperature (Fig. 4B) as well as the structure of ILs (Fig. 3D). It is worth pointing out that in water alone, PD was found to be nonfluorescent. ${ }^{20}$ Consistent with this assumption, we observed a linear correlation between the viscosity of $\left[\mathrm{C}_{4}-\mathrm{mim}\right] \mathrm{NO}_{3}$ with various amounts of water and the conformation of PD (Fig. 5). However, the slope was found to be drastically different, i.e., 7.7892 as compared to 5.1156, from that found for the temperature effect of the $\mathbf{P D}$ emission in $\left[\mathrm{C}_{4}\right.$-mim] $\mathrm{NO}_{3}$ (Fig. $4 \mathrm{~B}$ ), for example.

\section{Conclusions}

Overall, the structure of ILs appeared to have an effect on the conformation of PD. ILs promoted the opposite conformation as molecular solvents with similar viscosities, i.e., planar vs. twisted, respectively, and an order of magnitude larger viscosity of ILs was required to promote a similar amount of twisted PD. Specifically, the viscosity range at which twisted conformation becomes 


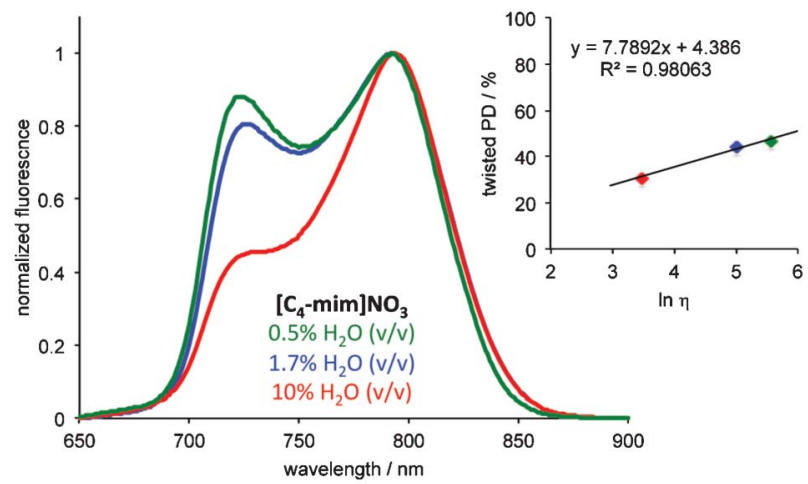

Fig. 5 Emission spectra of PD in $\left[\mathrm{C}_{4}\right.$-mim] $\mathrm{NO}_{3}$ as a function of the water content. Insert: effect of $\left[\mathrm{C}_{4}\right.$-mim] $\mathrm{NO}_{3}$ viscosity (red symbol $-10 \%$ of $\mathrm{H}_{2} \mathrm{O}$; blue symbol $1.7 \%$ of $\mathrm{H}_{2} \mathrm{O}$ and green $-0.5 \%$ of $\mathrm{H}_{2} \mathrm{O}$ ) as a function of PD conformation. Conditions: $[\mathrm{PD}]=1 \mu \mathrm{M}, \lambda_{\mathrm{ex}}=475 \mathrm{~nm},[\mathrm{DMSO}]=0.1 \%(\mathrm{v} / \mathrm{v})$.

dominant is shifted from $c a .40$ (in molecular solvents) to 400 (in ILs) mPa s range. There appeared to be linear correlations between PD's conformation and the viscosity in ILs, molecular solvent mixtures and single component molecular solvents.

However, the cation effect (in all ILs with a common cation a similar conformation of PD was present, regardless of viscosity) seemed to indicate that the structure of IL could control the conformation of PD. In this light, it is important to distinguish between properties of ILs that correlate with a given process and those that actually control the process. Hence, in ILs with short alkyl chain lengths i.e. $\left[\mathrm{C}_{4}-\mathrm{mim}\right]$ and $\left[\mathrm{C}_{2}-\mathrm{mim}\right]$, the solvent-solute interactions promoted the planar conformation, regardless of

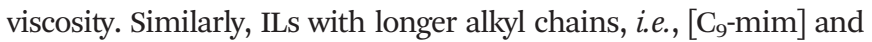
$\left[\mathrm{C}_{12}\right.$-mim], seemed to promote the twisted conformation, which happened to correlate with the increased viscosity of the solvent. However, it was apparent that the structure of ILs plays a more important role in the control of the PD conformation and the correlation between the ILs' viscosity and PD conformation might be coincidental. It should be noted that a microheterogenous nature of the ILs could be playing a role as well. ${ }^{31,32}$

While the exact nature of the observed phenomena remains to be elucidated, this report highlighted the designer solvent ability of ILs in that ILs of different structures gave rise to different PD conformations. Notably, an order of magnitude higher viscosity was required in ILs to induce a similar conformation of PD, potentially emphasising specific interactions between the ILs and PD.

\section{Acknowledgements}

This work was partially supported by the donors of the ACS Petroleum Research Fund (47965-G7 to SVD), by the University of Wyoming Start-up Funds (to MB), and by TCU start-up funds (to ZG). We would like to thank Fidelis N. Ngwa (UW) for the synthesis of the PD precursors, Professor Onofrio Annunziata (TCU-Chemistry) for helpful discussions, and
Professor Eric E. Simanek (TCU-Chemistry) for acquisition of and access to Lovis 2000ME/DMA $4500 \mathrm{M}$ instrument.

\section{Notes and references}

1 J. P. Hallet and T. Welton, Chem. Rev., 2011, 111, 3508.

2 M. H. G. Pretchtl and S. Sahler, Curr. Org. Chem., 2013, 17, 220.

3 Z. Fei and P. J. Dyson, Chem. Commun., 2013, 49, 2594.

4 A. Brandt, J. Graesvik, J. P. Hallett and T. Welton, Green Chem., 2013, 15, 550.

5 X. Sun, H. Luo and S. Dai, Chem. Rev., 2012, 112, 2100.

6 T. L. Greraves and C. J. Drummond, Chem. Soc. Rev., 2013, 42, 1096.

7 H. Weigawrtner, C. Cabrele and C. Herrmann, Phys. Chem. Chem. Phys., 2012, 14, 415.

8 C. Chiappe and D. Pieraccini, J. Phys. Org. Chem., 2005, 18, 275.

9 I. Newington, J. M. Perez-Arlandis and T. Welton, Org. Lett., 2007, 9, 5247.

10 M. J. Earle, S. P. Katdare and K. R. Seddon, Org. Lett., 2004, 6, 707.

11 S. V. Dzyuba and R. A. Bartsch, Tetrahedron Lett., 2002, 43, 4657.

12 L. P. Jameson and S. V. Dzyuba, J. Nat. Prod., 2011, 74, 310.

13 L. P. Jameson and S. V. Dzyuba, RSC Adv., 2013, 3, 4582.

14 V. Kumar, G. A. Baker and S. Pandey, Chem. Commun., 2011, 47, 4730.

15 D. C. Khara, J. P. Jaini, N. Mondal and A. Samanta, J. Phys. Chem. B, 2013, 117, 5156.

16 S. Mandal, S. Ghosh, C. Banerjee, J. Kuchlyan and N. Sarkar, J. Phys. Chem. B, 2013, 117, 6789.

17 B. Li, Y. Wnag, X. Wang, S. Vdovic, Q. Guo and A. Xia, J. Phys. Chem. B, 2012, 116, 13272.

18 S. Padney, S. N. Baker, S. Padney and G. A. Baker, J. Fluoresc., 2012, 22, 1313.

19 M. Balaz, H. A. Collins, E. Dahlstedt and H. L. Anderson, Org. Biomol. Chem., 2009, 7, 874.

20 M. K. Kuimova, S. W. Bothchway, A. W. Parker, M. Balaz, H. A. Collins, H. L. Anderson, K. Suhling and P. R. Ogilby, Nat. Chem., 2009, 1, 69.

21 M. A. Haidekker, T. P. Brady, D. Lichlyter and E. A. Theodorakis, J. Am. Chem. Soc., 2006, 128, 398.

22 M. K. Kuimova, Phys. Chem. Chem. Phys., 2012, 14, 12671.

23 A. Ahosseini and A. M. Scurto, Int. J. Thermophys., 2008, 29, 1222.

24 H. Shirota, T. Mandai, H. Fukazawa and T. Kato, J. Chem. Eng. Data, 2011, 56, 2453.

25 S. V. Dzyuba and R. A. Bartsch, ChemPhysChem, 2002, 3, 161.

26 B. Mokhrarani, A. Sharifi, H. R. Mortaheb, M. Mirzaei, M. Mafi and F. Sadeghian, J. Chem. Thermodyn., 2009, 41, 1432.

27 J. G. Huddleston, A. E. Visser, W. M. Reichert, H. D. Willauer, G. A. Broker and R. D. Rogers, Green Chem., 2001, 3, 156.

28 K. R. Seddon, A. Stark and M. Torres, Pure Appl. Chem., 2000, 72, 2275.

29 P. K. Mandal and A. Samanta, J. Phys. Chem. B, 2005, 109, 15172.

30 A. Samanta, J. Phys. Chem. Lett., 2010, 1, 1557.

31 A. Paul and A. Samanta, J. Phys. Chem. B, 2008, 112, 16626.

32 O. Russina, A. Triolo, L. Gontrani and R. Caminti, J. Phys. Chem. Lett., 2012, 3, 27. 